\title{
Polyphosphate Kinase 2 (PPK2) Enzymes: Structure, Function, and Roles in Bacterial Physiology and Virulence
}

\author{
Nolan Neville (D), Nathan Roberge and Zongchao Jia * \\ Department of Biomedical and Molecular Sciences, Queen's University, Kingston, ON K7L 3N6, Canada; \\ n.neville@queensu.ca (N.N.); 15nar2@queensu.ca (N.R.) \\ * Correspondence: jia@queensu.ca
}

\begin{abstract}
Inorganic polyphosphate (polyP) has been implicated in an astonishing array of biological functions, ranging from phosphorus storage to molecular chaperone activity to bacterial virulence. In bacteria, polyP is synthesized by polyphosphate kinase (PPK) enzymes, which are broadly subdivided into two families: PPK1 and PPK2. While both enzyme families are capable of catalyzing polyP synthesis, PPK1s preferentially synthesize polyP from nucleoside triphosphates, and PPK2s preferentially consume polyP to phosphorylate nucleoside mono- or diphosphates. Importantly, many pathogenic bacteria such as Pseudomonas aeruginosa and Acinetobacter baumannii encode at least one of each PPK1 and PPK2, suggesting these enzymes may be attractive targets for antibacterial drugs. Although the majority of bacterial polyP studies to date have focused on PPK1s, PPK2 enzymes have also begun to emerge as important regulators of bacterial physiology and downstream virulence. In this review, we specifically examine the contributions of PPK2s to bacterial polyP homeostasis. Beginning with a survey of the structures and functions of biochemically characterized PPK2s, we summarize the roles of PPK2s in the bacterial cell, with a particular emphasis on virulence phenotypes. Furthermore, we outline recent progress on developing drugs that inhibit PPK2 enzymes and discuss this strategy as a novel means of combatting bacterial infections.
\end{abstract}

Citation: Neville, N.; Roberge, N.; Jia, Z. Polyphosphate Kinase 2 (PPK2) Enzymes: Structure, Function, and Roles in Bacterial Physiology and Virulence. Int. J. Mol. Sci. 2022, 23, 670. https://doi.org/10.3390/ ijms 23020670

Academic Editors: Georg A. Sprenger and Andreas Burkovski

Received: 5 December 2021

Accepted: 7 January 2022

Published: 8 January 2022

Publisher's Note: MDPI stays neutral with regard to jurisdictional claims in published maps and institutional affiliations.

Keywords: polyphosphate; kinase; PPK2; virulence; Pseudomonas aeruginosa; inhibitor

\section{Introduction: Inorganic Polyphosphate and Polyphosphate Kinase 1 (PPK1)}

Inorganic polyphosphate (polyP) is an ancient and evolutionarily conserved biopolymer consisting of phosphate monomers linked together via high-energy phosphoanhydride bonds. PolyP chains can range in length from three to over one thousand inorganic phosphate $\left(P_{i}\right)$ residues [1]. Insoluble phosphate-containing granules-what we now know to be polyP-have been documented in bacteria since the late 1800s [2]. However, the source of this mysterious phosphate polymer remained unclear until Arthur Kornberg and colleagues isolated an enzyme from Escherichia coli that could synthesize polyP, which they termed polyphosphate kinase (PPK; later disambiguated as PPK1) [3]. It was not until 1990 that E. coli PPK1 was finally purified to homogeneity [4], which allowed for the identification and cloning of the $p p k 1$ gene, followed by overexpression and deletion studies [5-7]. The newfound ability to manipulate the $p p k 1$ gene was a boon for polyP research. E. coli mutants lacking $p p k 1$-and thus generating no detectable polyP-exhibited profound defects in stationary phase survival upon nutrient downshift [7-11]. PolyP has also been shown to protect bacteria from a variety of external stressors, such as heat [12], ultraviolet irradiation [13], antibiotics [14,15], metal ions [16], and oxidative stress [17,18]. Although it is not yet completely understood, at least some of these protective effects may be a result of chaperone-like function, whereupon polyP binds partially unfolded or denatured proteins to facilitate refolding once stress has abated [19].

Despite the absence of either PPK1 or PPK2 homologues in higher eukaryotes [20], it is worth noting that polyP has been detected in various mammalian cell types at concentrations typically ranging from 25 to $120 \mu \mathrm{M}$ [21], though this can reach approximately $1 \mathrm{mM}$

Copyright: () 2022 by the authors Licensee MDPI, Basel, Switzerland. This article is an open access article distributed under the terms and conditions of the Creative Commons Attribution (CC BY) license (https:// creativecommons.org/licenses/by/ $4.0 /)$. 
in platelets [22]. While the source of this mammalian polyP is unclear, it has been postulated that the mitochondrial $\mathrm{F}_{0} \mathrm{~F}_{1}$ ATPase is involved [23]. PolyP has been linked to diverse aspects of mammalian physiology, including blood clotting [24], bone formation [25], and protein polyphosphorylation [26-28]. PolyP also serves as a nucleation source for amyloid proteins ranging from human $\alpha$-synuclein and Tau to the E. coli biofilm protein CsgA [1,29]. Finally, several recent studies have demonstrated that bacterial polyP can modulate the mammalian immune response $[30,31]$, suggesting an intriguing potential for host-pathogen polyP crosstalk during infection [32].

\section{PPK2: A New Class of PolyP-Metabolizing Enzyme}

While most of the early work on bacterial polyP used E. coli (which encodes a single PPK1) as a model organism, other bacterial species such as Pseudomonas aeruginosa were eventually examined. The Kornberg lab observed that their $\Delta p p k 1$ knockout strain of $P$. aeruginosa still produced up to $20 \%$ of wildtype polyP levels $[33,34]$, in contrast to $\Delta p p k 1$ E. coli in which polyP is absent [6]. The source of this remaining polyP was later found to be a new class of enzyme termed PPK2 [34,35]. Remarkably, PPK2 shares no significant sequence identity with PPK1 [35]. Subsequent X-ray crystal structures of PPK2s from several species also corroborated a distinct structural fold relative to that of PPK1 [36]. On a functional level, P. aeruginosa PPK2 displayed a 75-fold preference for polyP degradation relative to synthesis, in contrast to PPK1 [34] (Figure 1). It therefore became clear that PPK1 and PPK2 were separate entities with distinct enzymology.

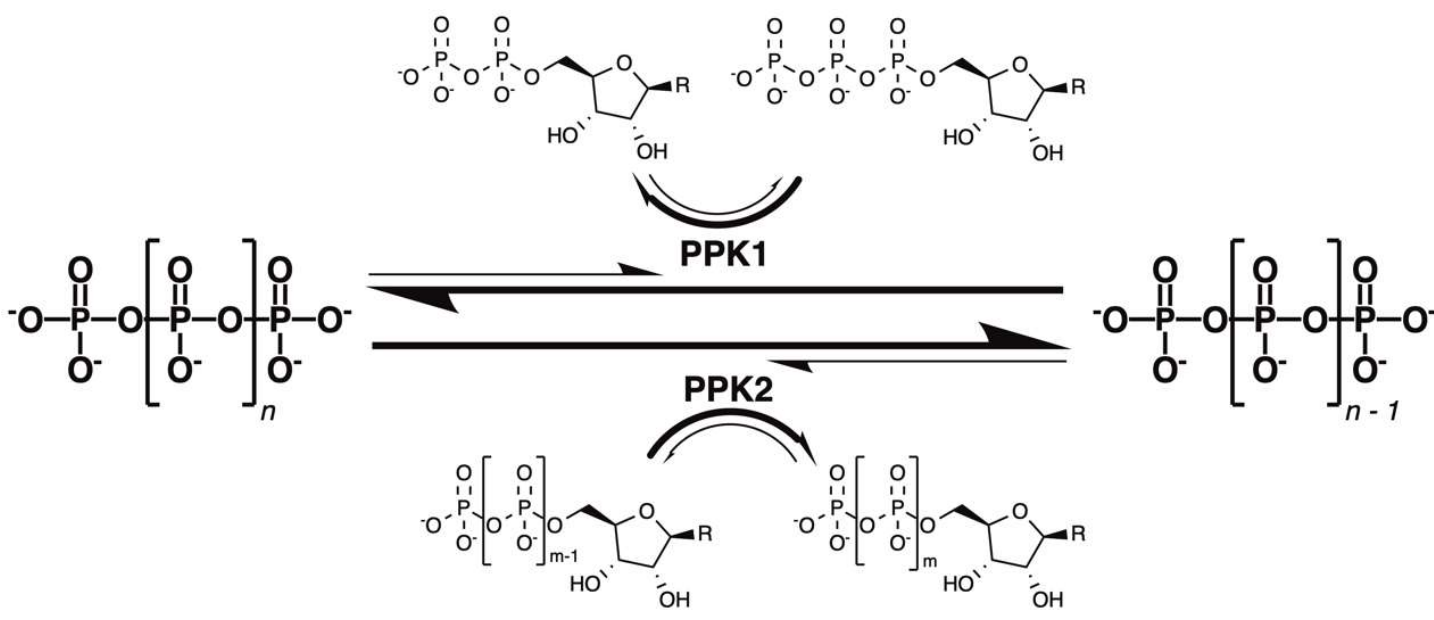

class I, m=2; class II, $\mathrm{m}=1$; class III, $\mathrm{m}=1$ or 2

Figure 1. Comparison of the reactions catalyzed by PPK1 and PPK2 enzymes. R, nucleobase.

Despite the absence of homology between PPK1 and PPK2, both respective classes of enzymes are highly conserved throughout the bacterial kingdom [35,37]. Interestingly, it is postulated that PPK2 is evolutionarily older than PPK1 based on phylogenetic analysis and trends in amino acid loss and gain [38]. ppk2 genes have been identified in many species of both Gram-positive and Gram-negative bacteria [35], with several species encoding multiple distinct isoforms $[35,39,40]$ (Table 1 ). For example, P. aeruginosa possesses three distinct PPK2s [39], whereas other pathogenic bacteria such as Mycobacterium tuberculosis [41] or Klebsiella pneumoniae [42] possess only a single PPK2 isoform. In a more extreme instance, the environmental bacterium Ralstonia eutropha contains five distinct PPK2 enzymes, further illustrating the genetic abundance and variability among PPK2s [40] (Table 1). By contrast, bacteria rarely encode more than one $p p k 1$ allele $[35,40,42]$. 
Table 1. Summary of bacterial species with characterized PPK2 enzymes.

\begin{tabular}{|c|c|c|c|c|}
\hline Species & Number of PPK2s & PPK2 Class & PDB ID & Reference \\
\hline Acinetobacter baumannii & 1 & II & & [42] \\
\hline Acinetobacter johnsonii & 1 & II & & {$[43,44]$} \\
\hline Agrobacterium tumefaciens & 1 & I & & {$[36,45]$} \\
\hline Arthrobacter aurescens & 1 & III & $3 \mathrm{RHF}$ & {$[46]$} \\
\hline Bacillus cereus & 1 & II & & [47] \\
\hline Campylobacter jejuni & 1 & $\mathrm{I}$ & & [48] \\
\hline Corynebacterium glutamicum & 2 & I & & [49] \\
\hline Cytophaga hutchinsonii & 1 & III & $\begin{array}{c}\text { 6ANG, 6ANH, 6ANQ, } \\
\text { 6AUO, 6AN9, 6B18 }\end{array}$ & [46] \\
\hline Deinococcus geothermalis & 1 & III & & [50] \\
\hline Deinococcus radiodurans & 1 & III & 6AQE, 7NMJ, 7BMM & {$[46,50]$} \\
\hline Delftia tsuruhatensis & 1 & III & & [51] \\
\hline Francisella tularensis & 1 & $\mathrm{I}$ & 4YEG, 5LLB, 5LL0, 5LLF & {$[52,53]$} \\
\hline Klebsiella pneumoniae & 1 & I & & [42] \\
\hline Meiothermus ruber & 1 & III & 5LC9 & {$[50,53]$} \\
\hline Meiothermus silvanus & 1 & III & & [50] \\
\hline Mycobacterium smegmatis & 1 & $\mathrm{I}$ & & [54] \\
\hline Mycobacterium tuberculosis & 1 & I & & {$[41,55]$} \\
\hline Myxococcus xanthus & 1 & II & & {$[56]$} \\
\hline \multirow{3}{*}{ Pseudomonas aeruginosa } & \multirow{3}{*}{3} & I (PPK2A/PA0141) & & {$[34,57]$} \\
\hline & & I (PPK2B/PA2428) & & {$[39,57]$} \\
\hline & & II (PPK2C/PA3455) & $3 \mathrm{CZP}$ & {$[36]$} \\
\hline Ralstonia eutropha & 5 & Not yet classified & & {$[40,58]$} \\
\hline Rhodopseudomonas palustris & 1 & I & & [36] \\
\hline Ruegeria pomeroyi & 1 & I & & [59] \\
\hline Sinorhizobium meliloti & 3 & $\mathrm{I}$ & $3 \mathrm{CZQ}, 6 \mathrm{DZG}$ & [36] \\
\hline Thermosynechococcus elongatus & 1 & III & & {$[50]$} \\
\hline
\end{tabular}

The tendency of bacteria to encode one or more PPK2 isoform has in turn complicated the study of polyP physiology. E. coli does not encode any PPK2s, and yet has served as the principal model species for studying bacterial polyP dynamics. As a result, our understanding of polyP dynamics in species other than E. coli has suffered. For example, in Acinetobacter baumannii-which is one of the few species known to encode multiple $p p k 1$ genes in addition to $p p k 2-\mathrm{knockout}$ of individual $p p k 1 \mathrm{~s}$ had differing consequences on virulence [42]. P. aeruginosa possesses three PPK2s, only two of which, however, can synthesize polyP in vivo to compensate for loss of PPK1 [39,57]. These studies challenge the validity of generalizing certain aspects of E. coli polyP biology to organisms that possess PPK2s, since these enzymes may play species-specific niche roles. Furthermore, the presence of PPK2s in many of the current priority bacterial pathogens such as P. aeruginosa and A. baumannii highlights the importance of understanding PPK2 biology in the fight against bacterial infections (Table 1) [42,57].

\section{PPK2 Enzymology}

A large body of phylogenetic, structural, and biochemical data exists for PPK2 enzymes. Sequence analysis suggests that PPK2s evolved from a common P-loop kinase 
ancestor with thymidylate kinases [36], which catalyze the phosphorylation of thymidine 5 -onophosphate by ATP to yield the essential DNA precursor thymidine 5'-diphosphate. P-loop kinases are characterized by a conserved Walker-A motif (GxxxGK) that interacts with the $\beta$-phosphate of the bound nucleotide, and a Walker B motif that mediates binding to the nucleotide $\gamma$-phosphate via $\mathrm{Mg}^{2+}$ coordinated to a conserved carboxylate residue [60]. Phylogenetic analysis, combined with published biochemical data for select enzymes, revealed that PPK2s can be classified into three subfamilies based on nucleoside phosphate substrate preference: class I phosphorylate nucleoside diphosphates, class II phosphorylate nucleoside monophosphates, and class III can phosphorylate both nucleoside mono- or diphosphates [50] (Figure 1). Class III PPK2s, along with a common ancestor of class I and II PPK2, were likely the first to emerge, followed by diversification of class I and class II PPK2s. Since broad specificity is thought to be a property of primordial enzymes [61], the promiscuity of class III PPK2s supports the idea that this class is the closest to the original PPK2 ancestor [50].

\subsection{PPK2 Crystal Structures and Catalytic Mechanism}

To date, the crystal structures of PPK2s from seven different bacterial species have been published (Table 1). These include representatives from all three classes: class I: Sinorhizobium meliloti (PDB ID 3CZQ) and Francisella tularensis (PDB ID 4YEG); class II: $P$. aeruginosa PPK2C/PA3455 (PDB ID 3CZP); and class III: Arthrobacter aurescens (PDB ID 3RHF), Meiothermus ruber (PDB ID 5LC9), Cytophaga hutchinsonii (PDB ID 6ANG), and Deinococcus radiodurans (PDB ID 6AQE) $[36,46,52,53]$. These structures reveal a similar overall PPK2 architecture resembling that of thymidylate kinase [62]. Each PPK2 displays a three-layered $\alpha-\beta-\alpha$ sandwich fold with a lid loop composed of two $\alpha$-helices. $\mathrm{An} \mathrm{Mg}^{2+}$ ion is frequently observed coordinated to the Walker A and/or Walker B motifs. The enzymes also share an internal substrate channel rich in positively charged residues that connect the polyP and nucleotide binding sites near the catalytic (Walker A) aspartate (Figure 2) [36,46,52,53]. Uniquely, the class II P. aeruginosa PPK2C has two fused PPK2 domains: a catalytically inactive $\mathrm{N}$-terminal and an active C-terminal [36]. A comparison of the above crystal structures revealed a class-specific signature residue located after the Walker B motif: class I is asparagine (N153 in S. meliloti PPK2), class II is glycine (G367 in PA3455), and class III is glutamate (E137 in C. hutchinsonii PPK2) [46,63].

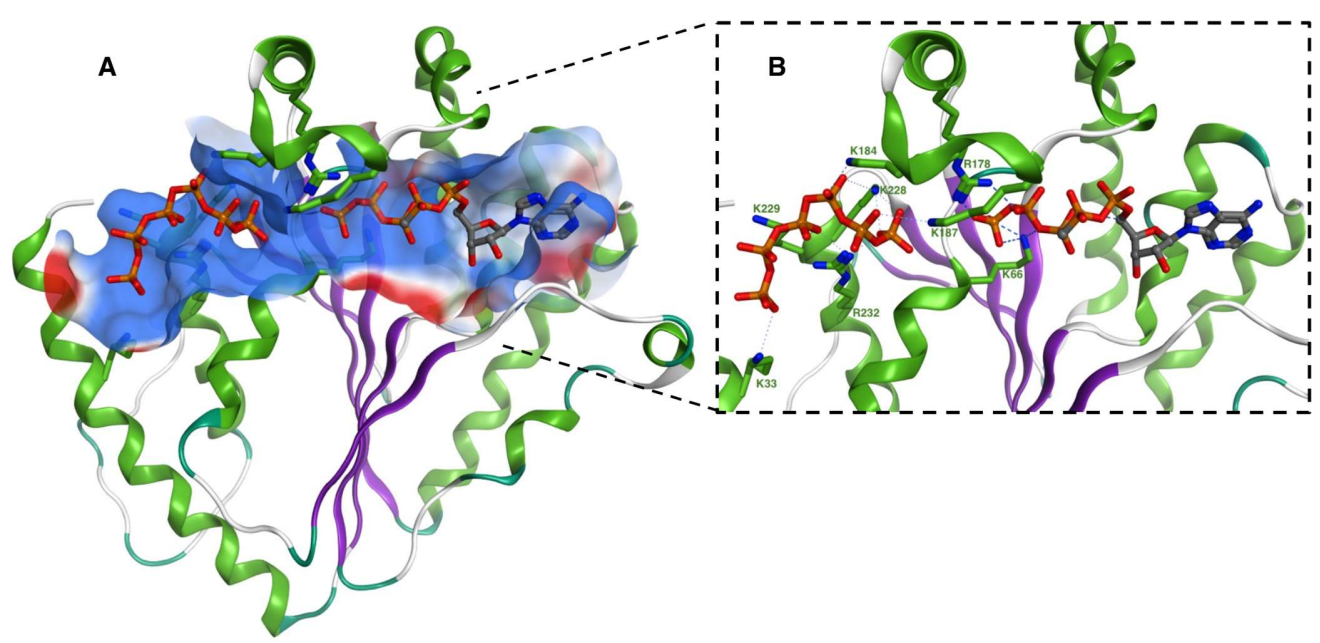

Figure 2. PPK2 substrate binding sites elucidated via co-crystallization with polyP and nucleotide ligand. F. tularensis PPK2 (green and purple) bound to polyP and the nucleotide AMP-PCH2PPP (PDB ID 5LLB) [53]. (A) Electrostatic surface representation of the polyP binding channel. Blue and red represent positive and negative charge, respectively. (B) Detailed view of the amino acid residues that mediate polyP binding. Interactions indicated by blue dashed lines. Figure created in Molecular Operating Environment. 
Several recent crystal structures of PPK2s complexed with polyP and/or nucleotides have provided invaluable insight into the substrate binding and reaction mechanisms of these enzymes. The class I $F$. tularensis PPK2 (FtPPK2) has been crystallized in complex with polyP alone (PDB ID 5LL0) and both polyP and $\beta, \gamma$-methylene adenosine $5^{\prime}$ pentaphosphate (AMP-PCPPP) (PDB ID 5LLB). The structures of class III M. ruber PPK2 (MrPPK2) in complex with ADP and PPi (PDB ID 5MAQ), AMP (PDB ID 5LCD), ADP (PDB ID 5LDB), and ATP (PDB ID 5LD1) have also been solved. Likewise, class III $C$. hutchinsonii PPK2 (ChPPK2) in complex with AMP (PDB ID 6ANG), ADP (PDB ID 6AN9), and guanosine 5-tetraphosphate (G4P) (PDB ID 6ANH) helps to further elucidate substrate specificity. FtPPK2 co-crystallized with polyP revealed a polyP chain nine $\mathrm{P}_{\mathrm{i}}$ units long bound between the protein core and the lid loop. The polyP is positioned by a cluster of lysine and arginine residues, which are conserved across all PPK2s [53] and reminiscent of the polyP tunnel observed in PPK1 [37] (Figure 2A). FtPPK2 co-crystallized with both polyP and the nucleotide $\beta, \gamma$-methylene adenosine $5^{\prime}$-triphosphate (AMP-PCP) yielded a structure in which two additional phosphoryl units were transferred onto AMP-PCP, yielding AMP-PCPPP. The nucleotide was bound on the right side of the Walker B motif, as predicted by a prior Nocek et al. study [36], with its five phosphate groups extending leftward towards the polyP channel, guided via coordination to the lid loop $\mathrm{Mg}^{2+}$ (Figure 2B). Although no electron density connecting the AMP-PCPPP to the polyP was visible, this spacing $(\sim 7.0 \AA)$ is consistent with the binding of six additional phosphoryl units. While intact polyP chains could not be observed in any of the MrPPK2 structures, individual phosphate ions were observed in the region corresponding to the polyP channel in FtPPK2. Alanine substitution of FtPPK2 K66, R118, and R178 resulted in weaker polyP binding and dramatically reduced enzyme activity [53]. Similarly, alanine substitution the corresponding residues (K86, K258, and R262) in ChPPK2 also markedly reduced activity. Nucleotide-bound structures of ChPPK2 in complex with AMP, ADP, and G4P, as well as D. radiodurans PPK2 (DrPPK2) in complex with ATP generally corroborated the binding orientations observed for FtPPK2 [46]. Interestingly, two ATP molecules were observed in one active site for DrPPK2 (PDB ID 6AQE). The first was bound in the typical nucleotide pocket, while the second was bound near the dimer interface [46]. Similarly, an Asn121Asp mutant of MrPPK2 also contained two ATP, with the adenosine moiety of the second ATP contacting the adjacent protomer (PDB ID 5O6M) [53]. It is tempting to speculate that this type of secondary nucleotide binding may serve as a regulatory mechanism, perhaps by influencing oligomeric state, which could potentially help explain the substrate inhibition phenomenon observed for other PPK2s [57]. While PPK2s from various species have been observed to form dimers, trimers, tetramers, and octamers in solution $[34,36,53,64]$, it is unclear how oligomerization affects activity or which oligomeric states are predominant in vivo.

Based on the described substrate-bound structures and complementary biochemical data, the PPK2 reaction mechanism is proposed to proceed via in-line nucleophilic attack by the nucleotide terminal phosphate oxygen on the terminal phosphorus atom of polyP [53]. The terminal phosphate groups of both substrates are coordinated by a bridging Lewis acidic $\mathrm{Mg}^{2+}$ (sometimes via a water molecule), which activates the polyP nucleophile. Several conserved positively charged residues located on the lid domain and the bottom of the active site (e.g., R208 and K81 of ChPPK2) serve to stabilize the transferred phosphoryl group of polyP via hydrogen-bonding and charge compensation [46,53]. It is worth noting that this mechanism is distinct from that of PPK1, in which an autophosphorylated histidine residue mediates transfer of phosphate between the nucleotide and the polyP chain $[4,37]$.

\subsection{Class I PPK2 Enzymology}

The following sections will summarize the biochemical characteristics of representative members of the class I, class II, and class III PPK2 families. The Kornberg lab conducted the first biochemical characterization of a class I PPK2 after having purified the enzyme to homogeneity from P. aeruginosa lysate. This enzyme (later called PPK2A/PA0141 to 
disambiguate from the other two P. aeruginosa PPK2s [39]) has a 75-fold preference for nucleoside diphosphate phosphorylation relative to polyP synthesis. Among nucleoside diphosphate acceptors, GDP is favored over ADP, as demonstrated by a roughly 2.5-fold lower Michaelis constant $\left(\mathrm{K}_{\mathrm{m}}\right)$. PPK2A shows no detectable AMP-phosphorylating activity; hence, it is a class I PPK2. Interestingly, $\mathrm{Mg}^{2+}$ is favored over $\mathrm{Mn}^{2+}$ for nucleoside diphosphate phosphorylation [34], but the inverse is true for polyP synthesis- $\mathrm{Mn}^{2+}$ elevates the PPK2A polyP synthesis rate to a level comparable to that of PPK1 [35]. A similar phenomenon was observed for the class I Corynebacterium glutamicum PPK2, which shows optimal activity with $\mathrm{Mn}^{2+}$, but remarkably exhibits a strong preference for polyP synthesis from ATP/GTP regardless of the cation provided [49]. A second class I P. aeruginosa enzyme PA2428 (dubbed PPK2B [39]) can readily phosphorylate ADP and GDP [36,65], and recent work from our lab has shown that this enzyme also exhibits exceptionally strong in vitro polyP synthesis activity from ATP, but only in the presence of an ATP regeneration system [57]. Other characterized class I enzymes include those of S. meliloti, Agrobacterium tumefaciens, Rhodopseudomonas palustris [36], Mycobacterium tuberculosis [54], and F. tularensis [52]. These enzymes fit the more traditional mold for class I PPK2s, demonstrating $\mathrm{Mg}^{2+}$-dependent ADP or GDP phosphorylation by polyP. An unusual member of the class I family is a PPK2 from Silicibacter (Ruegeria) pomeroyi-dubbed PPK3 by Nahalka and Patoprsty - that preferentially uses pyrimidine substrates [50,59]. Specifically, PPK3 catalyzed the polyP-dependent phosphorylation of CDP and UDP to CTP and UTP with roughly twofold higher activity compared to ADP/ATP and GDP/GTP [59]. Recently, two more class I enzymes were discovered to have the broadest nucleotide specificity to date. Both PPK2C from Ralstonia eutropha [66] and PPK2 ${ }_{\mathrm{AT}}$ from Agrobacterium tumefaciens were shown to phosphorylate ADP, GDP, CDP, dTDP, and UDP, in addition to performing the reverse reaction (polyP synthesis) from all five NTPs. This marks the first time PPK2s have been shown to use all the natural nucleotides-including thymidine-as substrates, highlighting the potential of these so-called universal PPK2s as tools for biotechnological NTP regeneration [66]. Specifically, universal PPK2s could be a boon for the regeneration of UTP and CTP required for the enzymatic synthesis of complex glycans $[59,67,68]$, in addition to more traditional ATP regeneration systems (reviewed in [63]).

\subsection{Class II PPK2 Enzymology}

Class II PPK2s catalyze nucleoside monophosphate phosphorylation, and the first member of this family to be discovered was an enzyme from Acinetobacter johnsonii (AjPPK2) initially termed polyP-AMP phosphotransferase (PAP) [69]. It was originally thought that this enzyme could only consume polyP, but subsequent experiments demonstrated that $A j P P K 2$ could also synthesize polyP from ADP. Indeed, AjPPK2 had similar polyP synthesis kinetic parameters $\left(\mathrm{K}_{\mathrm{m}}\right.$ and $\left.\mathrm{V}_{\text {max }}\right)$ to E. coli PPK1. PolyP consumption favored high $(100 \mathrm{mM})$ levels of $\mathrm{MgCl}_{2}$, whereas polyP synthesis was optimal at lower $(20 \mathrm{mM})$ levels of $\mathrm{MgCl}_{2}$, once again suggesting that metal ion availability in the cell may serve to regulate PPK2 reaction preference [43]. AjPPK2 was later shown to phosphorylate GMP and dAMP, but not CMP, UMP, or IMP [44]. Uniquely, the majority of PPK2s in the class II family contain two fused PPK2 domains and are thus roughly double the size of class I or III enzymes. However, the class II category contains both one-domain and two-domain PPK2s; therefore, prediction of biochemical activity based solely on the number of domains does not always hold true [50]. Both AjPPK2 and P. aeruginosa PPK2C (PA3455) are twodomain PPK2s. PPK2C exhibited optimal activity when phosphorylating AMP to ADP, but it could also phosphorylate GMP, dAMP, dGMP, IMP, and XMP. $\mathrm{Mg}^{2+}$ was the most effective cofactor, while $\mathrm{Co}^{2+}$ and $\mathrm{Ni}^{2+}$ yielded weak activity, and $\mathrm{Mn}^{2+}$ and $\mathrm{Ca}^{2+}$ had no activity. Unlike $A j P P K 2$, PPK2C had no detectable polyP synthesis activity under the conditions tested [36]. Characterized one-domain class II PPK2s include that of Myxococcus xanthus [56,70] and Bacillus cereus [47]. In contrast to AjPPK2 and P. aeruginosa PPK2C, M. xanthus PPK2/PAP had twofold higher activity in the presence of $\mathrm{Mn}^{2+}$ compared to $\mathrm{Mg}^{2+}[56]$. 


\subsection{Class III PPK2 Enzymology}

Class III is the most recently discovered PPK2 subfamily, capable of phosphorylating either nucleoside mono- or diphosphates. Based on their phylogenetic prediction of this new class of enzymes, Motomura and colleagues first validated PPK2s from M. ruber, Meiothermus silvanus, Deinococcus geothermalis, Thermosynechococcus elongatus, and $D$. radiodurans as capable of polyP-driven ATP synthesis from AMP [50]. Nocek et al. added two more class II enzymes to the list: A. aurescens (AaPPK2) and C. hutchinsonii (ChPPK2). ChPPK2, DrPPK2, and AaPPK2 all showed significant activity with $\mathrm{Mg}^{2+}, \mathrm{Mn}^{2+}, \mathrm{Ca}^{2+}$, $\mathrm{Co}^{2+}$, and $\mathrm{Ni}^{2+}$ [46], indicating that class III PPK2s appear to accept a broader range of metal ion cofactors relative to class I and II enzymes. As expected, the polyP synthesis activity of $A a \mathrm{PPK} 2, C h \mathrm{PPK} 2$, and DrPPK2 was at least three orders of magnitude lower than polyP-dependent phosphorylation of NMPs or NDPs. While M. ruber PPK2 was capable of using both purine and pyrimidine bases [50], AaPPK2, ChPPK2, and DrPPK2 showed no activity with pyrimidines. However, the latter three enzymes showed significant activity with dAMP and dADP, suggesting that these PPK2s may contribute to the synthesis of DNA precursors. Interestingly, these three class III PPK2s in addition to the class I SMc0218 and class II PA3455 showed weak adenylate kinase activity (conversion of ADP to AMP and ATP) [46]. An outstanding question surrounding class III PPK2s is whether the conversion of nucleoside monophosphates to nucleoside triphosphates involves a direct (pyrophosphorylation) or sequential transfer of phosphate groups. A recent study by Ogawa et al. concluded that a significant amount (30-80\%, depending on the PPK2 tested) of ATP produced from AMP occurs via pyrophosphorylation, and the rest occurs via step-by-step monophosphorylation by separate $P_{i}$ molecules [51]. While the authors of this study concede that their methodology could not exclude the possibility of some sequential monophosphorylation being mistaken for pyrophosphorylation, previous reports that PPK2 polyP utilization is processive $[34,35,69]$ - i.e., the polyP chain is not released by the enzyme between reactions-support the possibility that multiple $P_{i}$ units can be transferred from polyP at once. Regardless of the reaction mechanism, class III enzymes offer a streamlined means of recycling both AMP and ADP and are thus beginning to supplant class I enzymes for use in biotechnological ATP regeneration systems [63].

\subsection{Other PPK2 Activities}

Some PPK2 reaction products do not fit squarely within the categories described above. Moreover, the catalytic activities defining the three PPK2 classes should be considered preferences, rather than absolute definitions, as several class I and class II enzymes were recently shown to be capable of AMP phosphorylation to ATP in the presence of large (500 $\mu \mathrm{g} / \mathrm{mL}$ ) amounts of enzyme [63,71]. Several studies have also described unusual nucleoside phosphate species produced by PPK2s. Representative PPK2s from all three classes (SmPPK2, FtPPK2, AjPPK2, and MrPPK2) were shown to synthesize detectable levels of adenosine tetraphosphate (AP4) and adenosine pentaphosphate [71]. Similarly, the class III PPK2 from Delftia tsuruhatensis also makes AP4 [51]. Most recently, the class I A. tumefaciens PPK2 has been shown to catalyze the formation of oligophosphorylated nucleosides from GDP, CDP, dTDP, and UDP, with nona-phosphorylated adenosine being the largest product observed [45]. Crystallization of FtPPK2 with AMP-PCP and polyP resulted in a structure that clearly showed two extra phosphate groups added to AMP-PCP to yield AMP-PCPPP (Figure 2), though this species could not be detected in free solution enzyme reactions [53]. It remains to be determined whether these unorthodox PPK2 products are merely artifacts of in vitro reaction conditions, or if they also serve physiological functions in microbial systems. Ultraphosphates (branched polyphosphates) were recently shown to be a useable substrate for the enzyme alkaline phosphatase [72], raising the intriguing possibility that PPK enzymes could also consume, synthesize, or modify branched polyP chains. Moreover, cyclic polyphosphates (metaphosphates) have been detected in the polyP granules of the bacterium Xanthobacter autotrophicus [73]. Whether PPK enzymes play a role in the synthesis 
or utilization of these cyclic polyP molecules in bacteria remains an area ripe for future exploration.

\section{Roles of PPK2s in Bacterial Physiology and Virulence}

Although generally understudied compared to their PPK1 counterparts, PPK2 enzymes are being increasingly implicated as important regulators of bacterial physiology and virulence. The following sections will summarize the contributions of PPK2 enzymes to bacterial homeostasis, stress response, biofilms, cell invasion, and antibiotic susceptibility, as illustrated in Figure 3.

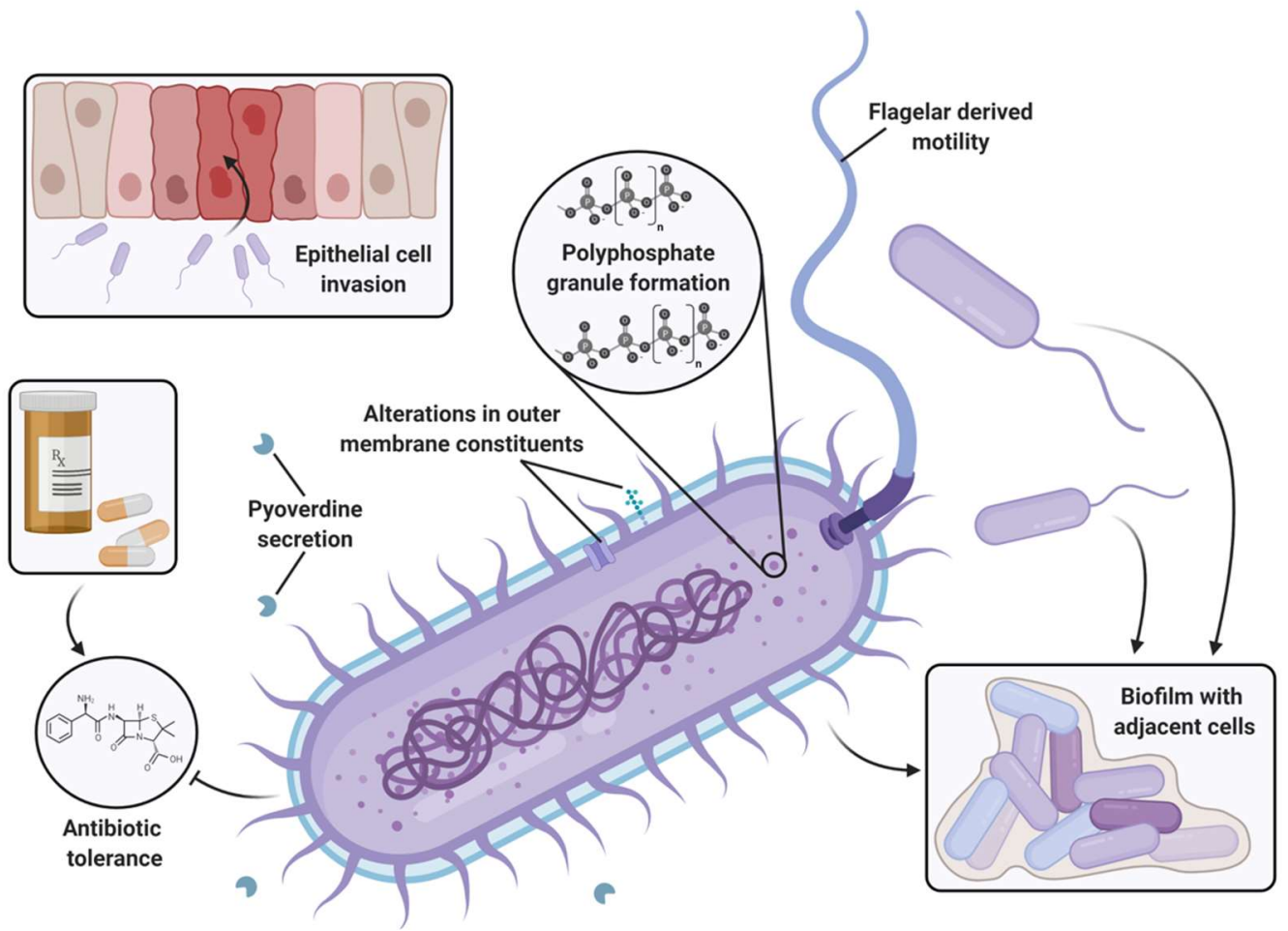

Figure 3. Schematic of bacterial virulence phenotypes linked to PPK2 enzymes. Figure created using BioRender.

\subsection{Bacterial Homeostasis and Stress Response}

P. aeruginosa has among the best-characterized PPK2 physiology to date. The Kornberg lab's initial studies of $P$. aeruginosa PPK2A (PA0141) revealed that expression of this enzyme was induced over 100-fold at stationary phase [34], suggesting its importance for stress survival. It is important to note that $P$. aeruginosa encodes three PPK2 enzymes: PPK2A (PA0141), PPK2B (PA2428), and PPK2C (PA33455), in addition to PPK1 (PA5242). Work by Racki et al. demonstrated that a quadruple knockout strain of P. aeruginosa PA14 lacking all four PPK enzymes $(\triangle p o l y P)$ was defective in cell cycle exit, which is dependent on the formation of organized polyP granules [39]. Importantly, there was no significant difference in growth kinetics between WT and $\triangle$ polyP PA14 [57]. As expected, the $\Delta p o l y P$ strain did not produce any detectable polyP, but a strain that retained functional PPK2A $(\triangle p p k 1 \Delta p p k 2 B \Delta p p k 2 C)$ still formed polyP granules and exhibited near-normal cell cycle exit. In contrast, individual presence of chromosomally encoded $p p k 2 B$ or $p p k 2 C$ was insufficient for polyP granule formation. Interestingly, when $p p k 2 B$ was re-introduced on a plasmid, it was sufficient to generate polyP granules [39], suggesting that PPK2B could also compensate for the loss of PPK1, provided that conditions are suitable for expression or otherwise full induction of enzymatic activity.

In Campylobacter jejuni, ppk2 deletion resulted in decreased polyP-dependent GTP synthesis. This yielded an increased intracellular ATP:GTP ratio but had no effect on 
polyP or guanosine tetraphosphate (ppGpp) alarmone levels. ppk2 deletion was also associated with significant variations in transcriptional abundance. For example, expression of the gene encoding SpoT-an enzyme which synthesizes and hydrolyzes ppGpp-was upregulated over 25-fold in the $\Delta p p k 2$ mutant, which the authors hypothesize may serve as a compensatory mechanism to keep ppGpp levels low. The C. jejuni ppk2 mutant was also defective in survival during stationary phase nutrient starvation, osmotic stress, and aerobic stress [48]. A ppk2 mutant strain of Mycobacterium smegmatis displayed a similarly elevated ATP:GTP ratio, indicating that PPK2 modulates nucleotide pools in vivo. M. smegmatis PPK2 has been shown to directly bind to nucleoside diphosphate kinase (Ndk) to direct its activity towards synthesis of GTP as opposed to CTP or UTP, which may contribute to the elevated ATP:GTP ratio. The M. smegmatis ppk2 mutant was also compromised in survival following thermal, acidic, and hypoxic stress. Double knockout of both ppk2 and ppk1 in M. smegmatis appears to be lethal [54], and repeated attempts to construct a C. jejuni ppk1-ppk2 double knockout were also unsuccessful [48], suggesting a critical role of polyP in these species. In Mycobacterium tuberculosis, a ppk2 transposon mutant accumulated significantly more intracellular polyP despite also exhibiting significantly reduced $p p k 1$ gene expression [41]. The M. tuberculosis ppk2 mutant also accumulated less glycerol-3phosphate, an important phospholipid precursor, and 1-deoxy-xylulose-5-phosphate, a peptidoglycan biosynthetic metabolite [74].

Remarkably, R. eutropha-an environmental bacterium known for its ability to grow using hydrogen as the electron donor-encodes seven $p p k$ genes: two $p p k 1$ and five $p p k 2$ genes. At least three of these enzymes (PPK1a, PPK2b, and PPK2c) contribute to polyP synthesis and at least four of them (PPK1a, PPK2c, PPK2d, and PPK2e) colocalize with polyP granules in vivo [40]. Overexpression of plasmid-encoded $p p k 2 c$ in an $R$. eutropha polyP-free background ( $\Delta p p k$-all) lacking all seven PPKs was sufficient to generate large polyP granules [75]. To study the contribution of these enzymes to R. eutropha physiology, Rosigkeit et al. tested the effects of various stressors on the $\Delta p p k$-all strain. Surprisingly, the $\Delta p p k$-all mutant showed no defects in heat shock survival, oxidative stress survival, or motility-all phenotypes that have previously been linked to PPK1 in E. coli [19,33,58]. The $\Delta p p k$-all mutant did display a marginal growth defect in phosphate-depleted media, indicating a role of polyP and PPK1/2s in R. eutropha phosphate storage [58]. Given the remarkable number of PPK2 enzymes in $R$. eutropha, it seems likely that additional roles for these enzymes remain to be discovered. The marked discrepancy in behavior between $R$. eutropha and E. coli ppk mutants in the face of stressors also serves to caution against broad generalizations of polyP functions between species, particularly when multiple PPK1 or PPK2 isoforms are present.

\subsection{Biofilms}

The Kornberg lab's initial discovery that P. aeruginosa PPK2A preferentially synthesizes GTP — a precursor for making the alginate found in Pseudomonad biofilms-led to speculation that PPK2A was important for biofilm formation [34]. Our group provided the first experimental evidence in support of this hypothesis, demonstrating that a $\Delta p p k 2 A \Delta p p k 2 B \Delta p p k 2 C$ mutant of $P$. aeruginosa PA14 was attenuated in biofilm formation relative to the WT, roughly mirroring the biofilm defect observed in the $\Delta p p k 1$ mutant. Biofilm formation of the $\triangle p o l y P$ strain lacking all four $p p k$ genes was even further attenuated compared to $\Delta p p k 2 A \Delta p p k 2 B \Delta p p k 2 C$ or $\Delta p p k 1$ [57]. Further research is needed to decipher the individual contribution of PPK2A, PPK2B, and PPK2C in biofilm formation. Similarly, a ppk2 transposon mutant of M. tuberculosis strain CDC1551 was shown to be defective in pellicle biofilm formation [74]. However, in a different study, $p p k 2$ deletion in $M$. tuberculosis strain H37Rv did not appear to affect biofilm formation upon visual inspection, although the authors did not quantify the biofilm [55]. This disagreement could be explained by the use of different parental strains, or the differing means of $p p k 2$ gene inactivation. Surprisingly, a $p p k 2$ mutant of $C$. jejuni formed significantly more biofilm than 
the WT [48]. Caution must therefore be taken when generalizing the relationship between PPK2 and biofilm from one species or strain to another.

\subsection{Virulence Factors and Invasion}

Virulence factors are broadly defined as bacterial products or phenotypes that enable colonization, replication, or dissemination within the host organism [76]. Motilitywhereby flagella or pili drive bacterial locomotion-is a necessity for the virulence of many species, and $p p k 2$ deletion ( $\triangle p p k 2 A \Delta p p k 2 B \Delta p p k 2 C)$ has been shown to reduce swimming motility in P. aeruginosa [57]. Likewise, secreted toxins such as the siderophore pyoverdine are another class of virulence factor that frequently underpin P. aeruginosa infections [77]. We showed that relative to the $P$. aeruginosa $\triangle p p k 1$ strain, the $\triangle p o l y P$ strain was further attenuated in pyoverdine production, thus implicating PPK2 enzymes in pyoverdine virulence. The $\triangle$ polyP strain also demonstrated a further reduction of $P$. aeruginosa virulence towards the nematode Caenorhabditis elegans relative to the $\Delta p p k 1$ strain, highlighting the importance of P. aeruginosa PPK2s in an animal model of infection for the first time [57]. Further studies to dissect the individual contributions of each $p p k 2$ isoform to these phenotypes may help elucidate the mechanistic links between polyP metabolism and virulence.

While $P$. aeruginosa is primarily an extracellular pathogen, PPK2 enzymes have also been extensively linked to the invasion and survival of the intracellular pathogens $C$. jejuni, M. tuberculosis, and F. tularensis. A C. jejuni ppk2 mutant was defective in invasion and intracellular survival in cultured human intestinal epithelial cells. Furthermore, $C$. jejuni $\Delta p p k 2$ was also significantly impaired in the colonization of day-old chickens [48]. These defects may be due to changes in outer membrane constituents (proteins, lipids, and polysaccharides), alterations of which in C. jejuni $\Delta p p k 2$ have been shown to attenuate its invasion [78]. In M. tuberculosis, ppk2 mutation or downregulation impaired growth and survival in macrophages $[41,54,55]$. Moreover, macrophages infected with $\Delta p p k 2$ bacteria secreted increased levels of proinflammatory cytokines [41], which culminated towards defects in colonization following bacterial challenge in both murine and guinea pig models of infection $[41,55]$. The lungs of guinea pigs infected with $\Delta p p k 2 M$. tuberculosis had fewer and smaller tubercles relative to the WT and ppk2-complemented controls [55]. Similarly, deletion of ppk2 (FTT_1564) in F. tularensis abolished polyP accumulation, and resulted in defective intracellular growth in macrophages and attenuated infection of mice [79].

\subsection{Antibiotic Sensitivity}

With the world facing a rising tide of antibiotic-resistant bacterial infections, an intriguing development has been the connection between polyP, PPKs, and antibiotic sensitivity. A $\triangle p p k 2 A$ strain of $P$. aeruginosa PAO1 showed increased susceptibility to several clinically relevant antibiotics, including imipenem and ciprofloxacin [80]. Likewise, an F. tularensis ppk2 mutant was more susceptible to three distinct classes of antibiotics: the aminoglycosides streptomycin and gentamicin, tetracyclines tetracycline and doxycycline, and the fluoroquinolone ciprofloxacin [52]. C. jejuni $\Delta p p k 2$ exhibited increased susceptibility to erythromycin and ciprofloxacin, which are considered drugs of choice for treating $C$. jejuni infections [48]. M. tuberculosis ppk2 mutation yielded increased susceptibility to the L,Dtranspeptidase inhibitor antibiotic meropenem, which could potentially be explained by the reduced transcription of L-D-transpeptidase genes observed in the ppk2 mutant [74]. In contrast, two independent reports showed that M. tuberculosis ppk2 mutants exhibit a fourfold increase in the minimum inhibitory concentration of isoniazid [41,55]. While the first four studies suggest the exciting possibility of inhibiting PPK2 enzymes to extend the lifespan of existing antibiotics, the isoniazid example behooves careful testing of potential PPK2 inhibitors in combination with antibiotics prior to clinical use.

\section{Therapeutic Potential: PPK2 Inhibitors}

Given the important roles of PPK2s in bacterial virulence and infection, these enzymes have been suggested as attractive drug targets. However, relatively few PPK2 inhibitors 
have been documented in vitro, and to the best of our knowledge, only one has been validated for PPK2 inhibition activity in vivo. A summary of published PPK2 inhibitors is provided in Table 2. Using a luciferase-based activity assay, Singh et al. screened a 2300-member National Cancer Institute small molecule library against purified maltose binding protein (MBP)-tagged M. tuberculosis PPK2. This screen identified the heteroaromatic compounds NSC 35676, NSC 30205, NSC 345647, and NSC 9037 as inhibitors of PPK2 at low-micromolar concentrations [55]. More recently, a series of (bis)phosphonic acid-derived PPK2 inhibitors have been developed [81]. Initially, three aryl phosphonate inhibitor molecules were co-crystallized with $C$. hutchinsonii PPK2, revealing the value of a (bis)phosphonate-based scaffold for PPK2 inhibition since this moiety was observed to competitively occupy the polyP channel [46]. A follow-up study synthesized 32 (bis)phosphonic acid derivatives, the best of which inhibited $C$. hutchinsonii PPK2 with an $\mathrm{IC}_{50}$ of approximately $60 \mu \mathrm{M}$ [81] (Table 2). The most potent PPK2 inhibitor documented to date is a G-quadruplex DNA aptamer that specifically binds $M$. tuberculosis PPK2 $\left(\mathrm{IC}_{50}=40 \mathrm{nM}\right)$ [64]. However, none of the aforementioned studies tested their inhibitors in bacteria. We recently discovered that the polyphenolic molecule gallein inhibits P. aeruginosa PPK1 and PPK2s in vitro at low-micromolar doses. Importantly, we showed that gallein also inhibits both PPK1 and PPK2s in the bacterial cell, phenocopying the $\triangle$ polyP strain (knockout lacking all four $p p k$ genes) to attenuate polyP accumulation, biofilm formation, pyoverdine production, and virulence in C. elegans. Gallein also synergized with the antibiotics tetracycline and ciprofloxacin to improve $C$. elegans survival following P. aeruginosa infection $[57,82]$. In a follow-up study, we also demonstrated that gallein inhibits A. baumannii and K. pneumoniae PPK2s in vitro [42] (Table 2).

Table 2. Chemical structures and activities of PPK2 inhibitors.

Inhibitor


Table 2. Cont.

\begin{tabular}{|c|c|c|c|c|}
\hline Inhibitor & Structure & Reaction Tested & Inhibition Potency & Reference \\
\hline $11 \mathrm{f}$ & & ATP synthesis from ADP & $\begin{array}{l}\mathrm{IC}_{50}=60.2 \mu \mathrm{M} \text { for } \\
\text { C. hutchinsonii PPK } 2\end{array}$ & \\
\hline $11 \mathrm{~g}$ & & ATP synthesis from ADP & $\begin{array}{l}\mathrm{IC}_{50}=70.5 \mu \mathrm{M} \text { for } \\
\text { C. hutchinsonii PPK2 }\end{array}$ & \\
\hline $11 \mathrm{i}$ & & ATP synthesis from ADP & $\begin{array}{l}\mathrm{IC}_{50}=58.0 \mu \mathrm{M} \text { for } \\
\text { C. hutchinsonii PPK2 }\end{array}$ & [81] \\
\hline $14 b$ & & ATP synthesis from ADP & $\begin{array}{l}\mathrm{IC}_{50}=85.4 \mu \mathrm{M} \text { for } \\
\text { C. hutchinsonii PPK2 }\end{array}$ & \\
\hline \multirow{5}{*}{ Gallein } & \multirow{5}{*}{$\mathrm{OH}$} & ATP synthesis from ADP & $\begin{array}{c}\mathrm{IC}_{50}=16 \mu \mathrm{M} \text { for } \\
\text { P. aeruginosa PPK2A }\end{array}$ & \multirow{3}{*}{ [57] } \\
\hline & & PolyP synthesis from ATP & $\begin{array}{c}\mathrm{IC}_{50}=20 \mu \mathrm{M} \text { for } \\
\text { P. aeruginosa PPK2B }\end{array}$ & \\
\hline & & ADP synthesis from AMP & $\begin{array}{l}\mathrm{IC}_{50}=165 \mu \mathrm{M} \text { for } \\
\text { P. aeruginosa PPK2C }\end{array}$ & \\
\hline & & ADP synthesis from AMP & $\begin{array}{l}\mathrm{IC}_{50}=40.7 \mu \mathrm{M} \text { for } \\
\text { A. baumannii PPK2 }\end{array}$ & \multirow{2}{*}{ [42] } \\
\hline & & ATP synthesis from ADP & $\begin{array}{c}\mathrm{IC}_{50}=50.4 \mu \mathrm{M} \text { for } \\
\text { K. pneumoniae MBP-PPK2 }\end{array}$ & \\
\hline Aptamer G9 & $\mathrm{N} / \mathrm{A}$ & ATP synthesis from ADP & $\begin{array}{c}\mathrm{IC}_{50}=39.3 \mathrm{nM} \text { for } \\
\text { M. tuberculosis PPK2 }\end{array}$ & [64] \\
\hline
\end{tabular}

\section{Conclusions and Future Outlook}

Our understanding of PPK2s has expanded rapidly since the discovery of this new class of enzymes nearly twenty years ago. The multitude of biochemical studies on purified PPK2s from diverse bacteria has provided a characterization of PPK2 enzymology that is arguably more thorough than that of PPK1s. However, where PPK2 research still lags behind PPK1 research is in studies of bacterial physiology. While $p p k 2$ deletion has been shown to influence stress response and virulence in several species, the resultant phenotypes appear to be less predictable than those observed in $p p k 1$ knockouts. Moreover, in species that possess both $p p k 1$ and $p p k 2$ genes-which include the priority pathogens $A$. baumannii, K. pneumoniae, and P. aeruginosa - the interplay between PPK1, PPK2, polyP, and downstream virulence phenotypes remains an area in need of further clarification. While the number of validated PPK2 inhibitors also trails in comparison to the number of validated PPK1 inhibitors, the abundance of structural and biochemical data now available for PPK2s suggests that the time is ripe for inhibitor development. Recent co-crystal structures of PPK2s in complex with inhibitors provide a promising roadmap for future structure-based drug design. Likewise, the availability of substrate-bound PPK2 structures has enhanced the prospects of in silico chemical library screening for inhibitors targeting either the nucleotide site or the polyP channel. As the role of PPK2s and polyP in bacterial physiology and virulence becomes more and more apparent, so too does the value of PPK2 enzymes as drug targets. PPK2 inhibitors, therefore, seem poised to become an important weapon in the fight against antibiotic-resistant bacteria. 
Author Contributions: Conceptualization, N.N. and Z.J.; Writing-original draft preparation, N.N. and N.R.; Writing—review and editing, N.N., N.R. and Z.J. All authors have read and agreed to the published version of the manuscript.

Funding: This research was funded by Cystic Fibrosis Canada (grant number 606292) and the Natural Sciences and Engineering Research Council of Canada (grant number RGPIN-2018-04427). N.N. and N.R. are supported by NSERC scholarships.

Institutional Review Board Statement: Not applicable.

Informed Consent Statement: Not applicable.

Data Availability Statement: Not applicable.

Acknowledgments: We thank Kody A. Klupt for helping generate Figure 2.

Conflicts of Interest: The authors declare no conflict of interest.

\section{Abbreviations}

$\begin{array}{ll}\text { AjPPK2 } & \text { Acinetobacter johnsonii PPK2 } \\ \text { AMP-PCP } & \beta, \gamma \text {-methylene adenosine } 5^{\prime} \text {-triphosphate } \\ \text { AMP-PCPPP } & \beta, \gamma \text {-methylene adenosine } 5^{\prime} \text {-pentaphosphate } \\ \text { AP4 } & \text { adenosine tetraphosphate } \\ \text { ChPPK2 } & \text { Cytophaga hutchinsonii PPK2 } \\ \text { DrPPK2 } & \text { Deinococcus radiodurans PPK2 } \\ \text { FtPPK2 } & \text { Francisella tularensis PPK2 } \\ \text { G4P } & \text { guanosine 5'-tetraphosphate } \\ \text { IC } 50 & \text { half-maximal inhibition constant } \\ \mathrm{K}_{\mathrm{m}} & \text { Michaelis constant } \\ \mathrm{MBP} & \text { maltose binding protein } \\ \mathrm{MrPPK} 2 & \text { Meiothermus ruber PPK2 } \\ \mathrm{Ndk} & \text { nucleoside diphosphate kinase } \\ \mathrm{PAP} & \text { polyP-AMP phosphotransferase } \\ \mathrm{P}_{\mathrm{i}} & \text { inorganic phosphate } \\ \text { polyP } & \text { polyphosphate } \\ \text { ppGpp } & \text { guanosine tetraphosphate } \\ \mathrm{PPK} & \text { polyphosphate kinase } \\ \text { SmPPK2 } & \text { Sinorhizobium meliloti PPK2 } \\ \mathrm{V}_{\mathrm{max}} & \text { maximum enzyme velocity }\end{array}$

\section{References}

1. Xie, L.; Jakob, U. Inorganic polyphosphate, a multifunctional polyanionic protein scaffold. J. Biol. Chem. 2019, 294 , 2180-2190. [CrossRef]

2. Meyer, A. Orientirende Untersuchungen Über Verbreitung Morphologie Und Chemie Des Volutins. Bot Zft 1904, $62,113-152$.

3. Kornberg, A.; Kornberg, S.; Simms, E.S. Metaphosphate synthesis by an enzyme from Escherichia coli. Biochim. Et Biophys. Acta (BBA)-Bioenerg. 1956, 20, 215-227. [CrossRef]

4. Ahn, K.; Kornberg, A. Polyphosphate kinase from Escherichia coli. Purification and demonstration of a phosphoenzyme intermediate. J. Biol. Chem. 1990, 265, 11734-11739. [CrossRef]

5. Akiyama, M.; Crooke, E.; Kornberg, A. The polyphosphate kinase gene of Escherichia coli. Isolation and sequence of the ppk gene and membrane location of the protein. J. Biol. Chem. 1992, 267, 22556-22561. [CrossRef]

6. Crooke, E.; Akiyama, M.; Rao, N.; Kornberg, A. Genetically altered levels of inorganic polyphosphate in Escherichia coli. J. Biol. Chem. 1994, 269, 6290-6295. [CrossRef]

7. Kuroda, A.; Murphy, H.; Cashel, M.; Kornberg, A. Guanosine Tetra- and Pentaphosphate Promote Accumulation of Inorganic Polyphosphate in Escherichia coli. J. Biol. Chem. 1997, 272, 21240-21243. [CrossRef]

8. Rao, N.N.; Kornberg, A. Inorganic polyphosphate supports resistance and survival of stationary-phase Escherichia coli. J. Bacteriol. 1996, 178, 1394-1400. [CrossRef]

9. Kuroda, A.; Tanaka, S.; Ikeda, T.; Kato, J.; Takiguchi, N.; Ohtake, H. Inorganic polyphosphate kinase is required to stimulate protein degradation and for adaptation to amino acid starvation in Escherichia coli. Proc. Natl. Acad. Sci.USA 1999, 96, 14264-14269. [CrossRef] 
10. Shiba, T.; Tsutsumi, K.; Yano, H.; Ihara, Y.; Kameda, A.; Tanaka, K.; Takahashi, H.; Munekata, M.; Rao, N.N.; Kornberg, A. Inorganic polyphosphate and the induction of rpoS expression. Proc. Natl. Acad. Sci. USA 1997, 94, 11210-11215. [CrossRef]

11. Rao, N.N.; Gómez-García, M.R.; Kornberg, A. Inorganic Polyphosphate: Essential for Growth and Survival. Annu. Rev. Biochem. 2009, 78, 605-647. [CrossRef] [PubMed]

12. Kim, K.-S.; Rao, N.N.; Fraley, C.D.; Kornberg, A. Inorganic polyphosphate is essential for long-term survival and virulence factors in Shigella and Salmonella spp. Proc. Natl. Acad. Sci. USA 2002, 99, 7675-7680. [CrossRef] [PubMed]

13. Nikel, P.I.; Chavarría, M.; Martínez-García, E.; Taylor, A.C.; de Lorenzo, V. Accumulation of inorganic polyphosphate enables stress endurance and catalytic vigour in Pseudomonas putida KT2440. Microb. Cell Factories 2013, 12, 50. [CrossRef] [PubMed]

14. Fraley, C.D.; Rashid, M.H.; Lee, S.S.K.; Gottschalk, R.; Harrison, J.; Wood, P.J.; Brown, M.R.W.; Kornberg, A. A polyphosphate kinase 1 (ppk1) mutant of Pseudomonas aeruginosa exhibits multiple ultrastructural and functional defects. Proc. Natl. Acad. Sci. USA 2007, 104, 3526-3531. [CrossRef]

15. Dahl, J.-U.; Gray, M.; Bazopoulou, D.; Beaufay, F.; Lempart, J.; Koenigsknecht, M.J.; Wang, Y.; Baker, J.R.; Hasler, W.L.; Young, V.B.; et al. The anti-inflammatory drug mesalamine targets bacterial polyphosphate accumulation. Nat. Microbiol. $2017,2,16267$. [CrossRef]

16. Beaufay, F.; Quarles, E.; Franz, A.; Katamanin, O.; Wholey, W.-Y.; Jakob, U. Polyphosphate Functions In Vivo as an Iron Chelator and Fenton Reaction Inhibitor. mBio 2020, 11, e01017-20. [CrossRef]

17. Gray, M.J.; Jakob, U. Oxidative stress protection by polyphosphate-New roles for an old player. Curr. Opin. Microbiol. 2015, 24, 1-6. [CrossRef]

18. Groitl, B.; Dahl, J.-U.; Schroeder, J.W.; Jakob, U. Pseudomonas aeruginosa defense systems against microbicidal oxidants. Mol. Microbiol. 2017, 106, 335-350. [CrossRef]

19. Gray, M.; Wholey, W.-Y.; Wagner, N.O.; Cremers, C.M.; Mueller-Schickert, A.; Hock, N.T.; Krieger, A.G.; Smith, E.M.; Bender, R.A.; Bardwell, J.C.; et al. Polyphosphate Is a Primordial Chaperone. Mol. Cell 2014, 53, 689-699. [CrossRef]

20. Brown, M.R.W.; Kornberg, A. Inorganic polyphosphate in the origin and survival of species. Proc. Natl. Acad. Sci. USA 2004, 101, 16085-16087. [CrossRef]

21. Kumble, K.D.; Kornberg, A. Inorganic Polyphosphate in Mammalian Cells and Tissues. J. Biol. Chem. 1995, $270,5818-5822$. [CrossRef] [PubMed]

22. Ruiz, F.A.; Lea, C.R.; Oldfield, E.; Docampo, R.; Gande, R.; Gibson, K.J.C.; Brown, A.K.; Krumbach, K.; Dover, L.G.; Sahm, H.; et al. Human Platelet Dense Granules Contain Polyphosphate and Are Similar to Acidocalcisomes of Bacteria and Unicellular Eukaryotes. J. Biol. Chem. 2004, 279, 44250-44257. [CrossRef]

23. Pavlov, E.; Aschar-Sobbi, R.; Campanella, M.; Turner, R.J.; Gómez-García, M.R.; Abramov, A.Y. Inorganic Polyphosphate and Energy Metabolism in Mammalian Cells. J. Biol. Chem. 2010, 285, 9420-9428. [CrossRef] [PubMed]

24. Morrissey, J.H.; Choi, S.H.; Smith, S. Polyphosphate: An ancient molecule that links platelets, coagulation, and inflammation. Blood 2012, 119, 5972-5979. [CrossRef] [PubMed]

25. Omelon, S.; Georgiou, J.; Henneman, Z.J.; Wise, L.M.; Sukhu, B.; Hunt, T.; Wynnyckyj, C.; Holmyard, D.; Bielecki, R.; Grynpas, M.D. Control of Vertebrate Skeletal Mineralization by Polyphosphates. PLoS ONE 2009, 4, e5634. [CrossRef]

26. Azevedo, C.; Livermore, T.; Saiardi, A. Protein Polyphosphorylation of Lysine Residues by Inorganic Polyphosphate. Mol. Cell 2015, 58, 71-82. [CrossRef] [PubMed]

27. Bentley-DeSousa, A.; Holinier, C.; Moteshareie, H.; Tseng, Y.-C.; Kajjo, S.; Nwosu, C.; Amodeo, G.F.; Bondy-Chorney, E.; Sai, Y.; Rudner, A.; et al. A Screen for Candidate Targets of Lysine Polyphosphorylation Uncovers a Conserved Network Implicated in Ribosome Biogenesis. Cell Rep. 2018, 22, 3427-3439. [CrossRef] [PubMed]

28. Bondy-Chorney, E.; Abramchuk, I.; Nasser, R.; Holinier, C.; Denoncourt, A.; Baijal, K.; McCarthy, L.; Khacho, M.; Lavallée-Adam, M.; Downey, M. A Broad Response to Intracellular Long-Chain Polyphosphate in Human Cells. Cell Rep. 2020, $33,108318$. [CrossRef] [PubMed]

29. Cremers, C.M.; Knoefler, D.; Gates, S.; Martin, N.; Dahl, J.-U.; Lempart, J.; Xie, L.; Chapman, M.; Galvan, V.; Southworth, D.R.; et al. Polyphosphate: A Conserved Modifier of Amyloidogenic Processes. Mol. Cell 2016, 63, 768-780. [CrossRef]

30. Roewe, J.; Stavrides, G.; Strueve, M.; Sharma, A.; Marini, F.; Mann, A.; Smith, S.A.; Kaya, Z.; Strobl, B.; Mueller, M.; et al. Bacterial polyphosphates interfere with the innate host defense to infection. Nat. Commun. 2020, 11, 4035. [CrossRef]

31. Rijal, R.; Cadena, L.A.; Smith, M.R.; Carr, J.F.; Gomer, R.H. Polyphosphate is an extracellular signal that can facilitate bacterial survival in eukaryotic cells. Proc. Natl. Acad. Sci. USA 2020, 117, 31923-31934. [CrossRef] [PubMed]

32. Bowlin, M.Q.; Gray, M.J. Inorganic polyphosphate in host and microbe biology. Trends Microbiol. 2021, 29, 1013-1023. [CrossRef] [PubMed]

33. Rashid, M.H.; Rao, N.N.; Kornberg, A. Inorganic Polyphosphate Is Required for Motility of Bacterial Pathogens. J. Bacteriol. 2000, 182, 225-227. [CrossRef]

34. Ishige, K.; Zhang, H.; Kornberg, A. Polyphosphate kinase (PPK2), a potent, polyphosphate-driven generator of GTP. Proc. Natl. Acad. Sci. USA 2002, 99, 16684-16688. [CrossRef] [PubMed]

35. Zhang, H.; Ishige, K.; Kornberg, A. A polyphosphate kinase (PPK2) widely conserved in bacteria. Proc. Natl. Acad. Sci. USA 2002, 99, 16678-16683. [CrossRef] 
36. Nocek, B.; Kochinyan, S.; Proudfoot, M.; Brown, G.; Evdokimova, E.; Osipiuk, J.; Edwards, A.M.; Savchenko, A.; Joachimiak, A.; Yakunin, A.F. Polyphosphate-dependent synthesis of ATP and ADP by the family-2 polyphosphate kinases in bacteria. Proc. Natl. Acad. Sci. USA 2008, 105, 17730-17735. [CrossRef] [PubMed]

37. Zhu, Y.; Huang, W.; Lee, S.S.K.; Xu, W. Crystal structure of a polyphosphate kinase and its implications for polyphosphate synthesis. EMBO Rep. 2005, 6, 681-687. [CrossRef]

38. Achbergerová, L.; Nahálka, J. PPK1 and PPK2-which polyphosphate kinase is older? Biologia 2014, 69, 263-269. [CrossRef]

39. Racki, L.R.; Tocheva, E.I.; Dieterle, M.; Sullivan, M.C.; Jensen, G.J.; Newman, D.K. Polyphosphate granule biogenesis is temporally and functionally tied to cell cycle exit during starvation in Pseudomonas aeruginosa. Proc. Natl. Acad. Sci. USA 2017, 114, E2440-E2449. [CrossRef]

40. Tumlirsch, T.; Sznajder, A.; Jendrossek, D. Formation of Polyphosphate by Polyphosphate Kinases and Its Relationship to Poly(3-Hydroxybutyrate) Accumulation in Ralstonia eutropha Strain H16. Appl. Environ. Microbiol. 2015, 81, 8277-8293. [CrossRef]

41. Chuang, Y.-M.; Belchis, D.A.; Karakousis, P.C. The Polyphosphate Kinase Gene ppk2 Is Required for Mycobacterium tuberculosis Inorganic Polyphosphate Regulation and Virulence. mBio 2013, 4, e00039-13. [CrossRef]

42. Roberge, N.; Neville, N.; Douchant, K.; Noordhof, C.; Boev, N.; Sjaarda, C.; Sheth, P.M.; Jia, Z. Broad-Spectrum Inhibitor of Bacterial Polyphosphate Homeostasis Attenuates Virulence Factors and Helps Reveal Novel Physiology of Klebsiella pneumoniae and Acinetobacter baumannii. Front. Microbiol. 2021, 12, 3229. [CrossRef] [PubMed]

43. Itoh, H.; Shiba, T. Polyphosphate Synthetic Activity of Polyphosphate:AMP Phosphotransferase in Acinetobacter johnsonii 210A. J. Bacteriol. 2004, 186, 5178-5181. [CrossRef] [PubMed]

44. Resnick, S.M.; Zehnder, A.J.B. In Vitro ATP Regeneration from Polyphosphate and AMP by Polyphosphate:AMP Phosphotransferase and Adenylate Kinase from Acinetobacter johnsonii 210A. Appl. Environ. Microbiol. 2000, 66, 2045-2051. [CrossRef]

45. Frank, C.; Teleki, A.; Jendrossek, D. Characterization of Agrobacterium tumefaciens PPKs reveals the formation of oligophosphorylated products up to nucleoside nona-phosphates. Appl. Microbiol. Biotechnol. 2020, 104, 9683-9692. [CrossRef] [PubMed]

46. Nocek, B.P.; Khusnutdinova, A.N.; Ruszkowski, M.; Flick, R.; Burda, M.; Batyrova, K.; Brown, G.; Mucha, A.; Joachimiak, A.; Berlicki, Ł.; et al. Structural Insights into Substrate Selectivity and Activity of Bacterial Polyphosphate Kinases. ACS Catal. 2018, 8, 10746-10760. [CrossRef]

47. Shi, X.; Rao, N.N.; Kornberg, A. Inorganic polyphosphate in Bacillus cereus: Motility, biofilm formation, and sporulation. Proc. Natl. Acad. Sci. USA 2004, 101, 17061-17065. [CrossRef]

48. Gangaiah, D.; Liu, Z.; Arcos, J.; Kassem, I.; Sanad, Y.; Torrelles, J.B.; Rajashekara, G. Polyphosphate Kinase 2: A Novel Determinant of Stress Responses and Pathogenesis in Campylobacter jejuni. PLoS ONE 2010, 5, e12142. [CrossRef]

49. Lindner, S.N.; Vidaurre, D.; Willbold, S.; Schoberth, S.M.; Wendisch, V.F. NCgl2620 Encodes a Class II Polyphosphate Kinase in Corynebacterium glutamicum. Appl. Environ. Microbiol. 2007, 73, 5026-5033. [CrossRef]

50. Motomura, K.; Hirota, R.; Okada, M.; Ikeda, T.; Ishida, T.; Kuroda, A. A New Subfamily of Polyphosphate Kinase 2 (Class III PPK2) Catalyzes both Nucleoside Monophosphate Phosphorylation and Nucleoside Diphosphate Phosphorylation. Appl. Environ. Microbiol. 2014, 80, 2602-2608. [CrossRef]

51. Ogawa, M.; Uyeda, A.; Harada, K.; Sato, Y.; Kato, Y.; Watanabe, H.; Honda, K.; Matsuura, T. Class III Polyphosphate Kinase 2 Enzymes Catalyze the Pyrophosphorylation of Adenosine-5'-Monophosphate. ChemBioChem 2019, 20, 2961-2967. [CrossRef]

52. Batten, L.E.; Parnell, A.E.; Wells, N.J.; Murch, A.L.; Oyston, P.C.F.; Roach, P.L. Biochemical and structural characterization of polyphosphate kinase 2 from the intracellular pathogen Francisella tularensis. Biosci. Rep. 2016, 36, e00294. [CrossRef]

53. Parnell, A.; Mordhorst, S.; Kemper, F.; Giurrandino, M.; Prince, J.P.; Schwarzer, N.J.; Hofer, A.; Wohlwend, D.; Jessen, H.; Gerhardt S.; et al. Substrate recognition and mechanism revealed by ligand-bound polyphosphate kinase 2 structures. Proc. Natl. Acad. Sci. USA 2018, 115, 3350-3355. [CrossRef]

54. Sureka, K.; Sanyal, S.; Basu, J.; Kundu, M. Polyphosphate kinase 2: A modulator of nucleoside diphosphate kinase activity in mycobacteria. Mol. Microbiol. 2009, 74, 1187-1197. [CrossRef] [PubMed]

55. Singh, M.; Tiwari, P.; Arora, G.; Agarwal, S.; Kidwai, S.; Singh, R. Establishing Virulence Associated Polyphosphate Kinase 2 as a drug target for Mycobacterium tuberculosis. Sci. Rep. 2016, 6, 26900. [CrossRef] [PubMed]

56. Kimura, Y.; Kamatani, S. Catalytic activity profile of polyP:AMP phosphotransferase from Myxococcus xanthus. J. Biosci. Bioeng. 2021, 131, 147-152. [CrossRef] [PubMed]

57. Neville, N.; Roberge, N.; Ji, X.; Stephen, P.; Lu, J.L.; Jia, Z. A Dual-Specificity Inhibitor Targets Polyphosphate Kinase 1 and 2 Enzymes To Attenuate Virulence of Pseudomonas aeruginosa. mBio 2021, 12, e0059221. [CrossRef]

58. Rosigkeit, H.; Kneißle, L.; Obruča, S.; Jendrossek, D. The Multiple Roles of Polyphosphate in Ralstonia eutropha and Other Bacteria. Microb. Physiol. 2021, 31, 163-177. [CrossRef]

59. Nahálka, J.; Pätoprstý, V. Enzymatic synthesis of sialylation substrates powered by a novel polyphosphate kinase (PPK3). Org. Biomol. Chem. 2009, 7, 1778-1780. [CrossRef]

60. Leipe, D.D.; Koonin, E.V.; Aravind, L. Evolution and Classification of P-loop Kinases and Related Proteins. J. Mol. Biol. 2003, 333, 781-815. [CrossRef]

61. Amar, D.; Berger, I.; Amara, N.; Tafa, G.; Meijler, M.M.; Aharoni, A. The Transition of Human Estrogen Sulfotransferase from Generalist to Specialist Using Directed Enzyme Evolution. J. Mol. Biol. 2012, 416, 21-32. [CrossRef] [PubMed]

62. Fioravanti, E.; Haouz, A.; Ursby, T.; Munier-Lehmann, H.; Delarue, M.; Bourgeois, D. Mycobacterium tuberculosis Thymidylate Kinase: Structural Studies of Intermediates along the Reaction Pathway. J. Mol. Biol. 2003, 327, 1077-1092. [CrossRef] 
63. Tavanti, M.; Hosford, J.; Lloyd, R.C.; Brown, M.J.B. Recent Developments and Challenges for the Industrial Implementation of Polyphosphate Kinases. Chem CatChem 2021, 13, 3565-3580. [CrossRef]

64. Shum, K.T.; Lui, E.L.H.; Wong, S.C.K.; Yeung, P.; Sam, L.; Wang, Y.; Watt, R.M.; Tanner, J.A. Aptamer-Mediated Inhibition of Mycobacterium tuberculosis Polyphosphate Kinase 2. Biochemistry 2011, 50, 3261-3271. [CrossRef] [PubMed]

65. Rexer, T.F.; Schildbach, A.; Klapproth, J.; Schierhorn, A.; Mahour, R.; Pietzsch, M.; Rapp, E.; Reichl, U. One pot synthesis of GDP-mannose by a multi-enzyme cascade for enzymatic assembly of lipid-linked oligosaccharides. Biotechnol. Bioeng. 2017, 115, 192-205. [CrossRef]

66. Hildenbrand, J.C.; Teleki, A.; Jendrossek, D. A universal polyphosphate kinase: PPK2c of Ralstonia eutropha accepts purine and pyrimidine nucleotides including uridine diphosphate. Appl. Microbiol. Biotechnol. 2020, 104, 6659-6667. [CrossRef]

67. Mahour, R.; Klapproth, J.; Rexer, T.F.; Schildbach, A.; Klamt, S.; Pietzsch, M.; Rapp, E.; Reichl, U. Establishment of a five-enzyme cell-free cascade for the synthesis of uridine diphosphate N-acetylglucosamine. J. Biotechnol. 2018, 283, 120-129. [CrossRef]

68. Gottschalk, J.; Blaschke, L.; Aßmann, M.; Kuballa, J.; Elling, L. Integration of a Nucleoside Triphosphate Regeneration System in the One-pot Synthesis of UDP-sugars and Hyaluronic Acid. ChemCatChem 2021, 13, 3074-3083. [CrossRef]

69. Bonting, C.F.; Kortstee, G.J.; Zehnder, A.J. Properties of polyphosphate: AMP phosphotransferase of Acinetobacter strain 210A. J. Bacteriol. 1991, 173, 6484-6488. [CrossRef]

70. Zhang, H.; Rao, N.N.; Shiba, T.; Kornberg, A. Inorganic polyphosphate in the social life of Myxococcus xanthus: Motility, development, and predation. Proc. Natl. Acad. Sci. USA 2005, 102, 13416-13420. [CrossRef]

71. Mordhorst, S.; Singh, J.; Mohr, M.K.F.; Hinkelmann, R.; Keppler, M.; Jessen, H.J.; Andexer, J.N. Several Polyphosphate Kinase 2 Enzymes Catalyse the Production of Adenosine 5'-Polyphosphates. ChemBioChem 2018, 20, 1019-1022. [CrossRef]

72. Dürr-Mayer, T.; Qiu, D.; Eisenbeis, V.B.; Steck, N.; Häner, M.; Hofer, A.; Mayer, A.; Siegel, J.S.; Baldridge, K.K.; Jessen, H.J. The chemistry of branched condensed phosphates. Nat. Commun. 2021, 12, 5368. [CrossRef]

73. Mandala, V.S.; Loh, D.M.; Shepard, S.M.; Geeson, M.B.; Sergeyev, I.V.; Nocera, D.G.; Cummins, C.C.; Hong, M. Bacterial Phosphate Granules Contain Cyclic Polyphosphates: Evidence from 31P Solid-State NMR. J. Am. Chem. Soc. 2020, 142, 1840718421. [CrossRef]

74. Chuang, Y.-M.; Dutta, N.K.; Hung, C.-F.; Wu, T.-C.; Rubin, H.; Karakousis, P.C. Stringent Response Factors PPX1 and PPK2 Play an Important Role in Mycobacterium tuberculosis Metabolism, Biofilm Formation, and Sensitivity to Isoniazid In Vivo. Antimicrob. Agents Chemother. 2016, 60, 6460-6470. [CrossRef]

75. Hildenbrand, J.C.; Reinhardt, S.; Jendrossek, D. Formation of an Organic-Inorganic Biopolymer: PolyhydroxybutyratePolyphosphate. Biomacromolecules 2019, 20, 3253-3260. [CrossRef]

76. Cross, A.S. What is a virulence factor? Crit. Care 2008, 12, 197. [CrossRef]

77. Kang, D.; Revtovich, A.V.; Chen, Q.; Shah, K.N.; Cannon, C.L.; Kirienko, N.V. Pyoverdine-Dependent Virulence of Pseudomonas aeruginosa Isolates From Cystic Fibrosis Patients. Front. Microbiol. 2019, 10, 2048. [CrossRef]

78. Pina-Mimbela, R.; Madrid, J.A.; Kumar, A.; Torrelles, J.B.; Rajashekara, G. Polyphosphate Kinases Modulate Campylobacter Jejuni Outer Membrane Constituents and Alter Its Capacity to Invade and Survive in Intestinal Epithelial Cells In Vitro. Emerg. Microbes Infect. 2015, 4, e77. [CrossRef] [PubMed]

79. Richards, M.I.; Michell, S.L.; Oyston, P.C.F. An intracellularly inducible gene involved in virulence and polyphosphate production in Francisella. J. Med. Microbiol. 2008, 57, 1183-1192. [CrossRef] [PubMed]

80. Ortiz-Severín, J.; Varas, M.; Bravo-Toncio, C.; Guiliani, N.; Chávez, F.P. Multiple antibiotic susceptibility of polyphosphate kinase mutants (ppk1 and ppk2) from Pseudomonas aeruginosa PAO1 as revealed by global phenotypic analysis. Biol. Res. 2015, 48, 1-6. [CrossRef] [PubMed]

81. Burda-Grabowska, M.; Macegoniuk, K.; Flick, R.; Nocek, B.P.; Joachimiak, A.; Yakunin, A.F.; Mucha, A.; Berlicki, Ł. Bisphosphonic acids and related compounds as inhibitors of nucleotide- and polyphosphate-processing enzymes: A PPK1 and PPK2 case study. Chem. Biol. Drug Des. 2019, 93, 1197-1206. [CrossRef] [PubMed]

82. Baijal, K.; Downey, M. Targeting Polyphosphate Kinases in the Fight against Pseudomonas aeruginosa. mBio 2021, 12, 0147721 [CrossRef] [PubMed] 